\title{
Application of starch-albumen powder as breading material in fried foods: An optimization study
}

\section{Taofik Akinyemi Shittu, Oluwaseun Ogunjinmi, Ibukun Adekola Ola, Olajide} Philip Sobukola, Olajide Mark Sogunle, Tajudeen Muraina Olayanju \& Olawale Usman Dairo

To cite this article: Taofik Akinyemi Shittu, Oluwaseun Ogunjinmi, Ibukun Adekola Ola, Olajide Philip Sobukola, Olajide Mark Sogunle, Tajudeen Muraina Olayanju \& Olawale Usman Dairo (2016) Application of starch-albumen powder as breading material in fried foods: An optimization study, Journal of Culinary Science \& Technology, 14:1, 22-35

To link to this article: http://dx.doi.org/10.1080/15428052.2015.1058207

曲 Published online: 09 Dec 2015.

Submit your article to this journal

a

View related articles $\widetilde{ }$

View Crossmark data $₫$ 


\title{
Application of starch-albumen powder as breading material in fried foods: An optimization study
}

\author{
Taofik Akinyemi Shittua, Oluwaseun Ogunjinmi ${ }^{a}$, Ibukun Adekola Olab, \\ Olajide Philip Sobukola ${ }^{a}$, Olajide Mark Sogunlec, Tajudeen Muraina Olayanju ${ }^{b}$ \\ and Olawale Usman Dairob
}

\begin{abstract}
aDeparment of Food Science and Technology, Federal University of Agriculture, Abeokuta, Ogun State, Nigeria; 'bepartment of Agricultural Engineering, Federal University of Agriculture, Abeokuta, Ogun State, Nigeria; 'Department of Animal Production and Health, Federal University of Agriculture Abeokuta, Ogun State, Nigeria
\end{abstract}

\begin{abstract}
The potential of using starch-albumen powder (SAP) as solid coating powder for fried food application was studied. Egg albumen was mixed with $10-30 \%$ dried starch and dried at $40-60^{\circ} \mathrm{C}$ air velocity of $4.5 \mathrm{~m} / \mathrm{s}$ to produce SAP. SAP was used to coat wet yam chips prior to frying at $180^{\circ} \mathrm{C}$ for $3 \mathrm{~min}$. The drying temperature and starch content in SAP significantly affected the oil uptake and moisture of fried chips. The increased amount of albumen (or reduced starch) content significantly reduced oil uptake. The sensory attributes influenced the overall acceptability of the fried chips in the order of taste $>$ flavor $>$ texture $>$ appearance. To minimize oil uptake and moisture content and maximize acceptability of the fried chips, SAP dried at temperature of $40^{\circ} \mathrm{C}$ with starch content of $11.3 \%$ should be used. The study further indicates the potential of using SAP as coating in some other food products.
\end{abstract}

\section{ARTICLE HISTORY}

Received 5 December 2014

Revised 24 December 2014

Accepted 1 June 2015

\section{KEYWORDS}

Coating; fried yam chips; oil uptake; optimization; starch-albumen powder

\section{Introduction}

Poultry egg is a highly perishable agricultural product and shows rapid quality deterioration within a maximum of two weeks when stored at room temperature (Silversides \& Scott, 2001) due to its high moisture and protein content favorable to microbial growth. Consequently, a powdered form of poultry egg is preferred by food handlers and processors due to its greater stability and convenience in handling and use.

Egg powder (EP) is a common ingredient in the meat, bakery, and confectionery food industry due to its excellent foaming, gelling, and emulsifying functions. Although, the presence of egg yolk material in EP gives it the emulsifying function, however, for health reasons, consumers often avoid yolk-containing products due to higher risk of coronary disease attributed to

CONTACT Taofik Akinyemi Shittu staofeek0904@yahoo.com 0 Department of Food Science and Technology, Federal University of Agriculture, Abeokuta, Ogun State, Nigeria.

Color versions of one or more of the figures in the article can be found online at www.tandfonline.com/wcsc. 
cumulative effect of cholesterol deposit in the blood vessel lining. Because of the high cholesterol content of yolk, the application of high heat during spray drying its presence in EP can also predispose the product to oxidative changes leading to production of oxysterol-a highly toxic compound-as well as off odor development in the product during storage. Thus, egg white powder or its derivatives without yolk materials would be a better alternative where emulsifying function is not required. Consequently, starch-albumen powder (SAP) was conceived partly as a preserved and more stable form of liquid egg white and also as a healthier ingredient to replace whole egg powder due to the absence of cholesterol-containing yolk (Shittu \& Ikpasa, 2006).

Reports have shown that pan-dried albumen (egg white) powders have better quality than spray dried alternatives (Bergquist, 1986) due to little or no alteration of functionality in the latter than the former. However, pan drying of albumen may be too slow, high energy consuming, and throughput is not commercially feasible. Pre-concentration of albumen prior to drying could be used to decrease the energy demand and improve the capacity of such a dryer (Mohr, Kleinschmidt, \& Borgwardt, 1987). We have previously reported that the addition of dried starch to reduce the initial moisture content of egg albumen led to about $21 \%$ reduction of drying time. A new food product also known as SAP was obtained with functional properties that could make it find several applications in food processing (Shittu, Idowu, \& Ademosun, 2010). Therefore, in order to confirm the prospective use of SAP as a food ingredient in food processing, its functionality must be matched up with specific uses.

Fried yam chips are a common fast food popularly consumed as a main dish in homes and eateries in many parts of sub-Saharan Africa. Due to its simple method and relatively short preparation time, it is consumed as a street (or fast) food. Fried yam chips coated with whipped whole egg are another way of preparing the product. Due to some health reasons, some consumers may prefer egg white as a coating to avoid consuming the cholesterol found in whipped whole egg (Alimi et al., 2013). Starch powder has been widely used as a simple coating material or solid carrier for other coating mixes for food applications (Satin, 2014). To the best of our knowledge, no single report has been published to showcase the potential of SAP for similar culinary purpose.

Coating of food particles prior to frying has long been practiced. Previous studies have shown that the batter and/or breading adhering to a food product after frying often modifies certain sensorial properties (appearance, flavor/taste, and texture) of fried food products (Alimi, Shittu, Sanni, \& Arowolo, 2013). To prepare coating batter or film, some quantity of dry coating material is reconstituted in a solvent (mostly water) to varying concentrations and viscosities, depending on the product requirement. Breading materials are, on the other hand, applied as a coating in powder form on the food particles. Previous studies have shown that coating powder pick-up by the food particle surface (Maskat et al., 2005) is an important 
functional property of breading (or coating) material in fried food applications. The powder pick-up is due to adherence of solid particles to the food surface, which is also determined by the degree of food surface wetness, finish, and absorption/adsorption property of the coating material (Alimi, Shittu, \& Sanni, 2014). Thus, the water absorption capacity of the coating material is an important functional property that determines the coating powder's ability to be wetted and get adhered to the product's surface. This, in turn, may affect the coating pick-up and frying loss of coating material. The amount of coating material picked up has also been reported to significantly influence surface color development in fried products (AbuAli, 2004). Also, oil absorption capacity may determine the extent to which a coating material allows absorption and retention of oil into its matrix. Hence, it could influence the frying oil uptake by coated product.

The goal of many of previously reported studies has been the reduction of oil content in fried food products. Consistently, coating (or breading) food materials prior to frying helped in reducing oil uptake (Albert \& Mittal, 2002; Gennadios, Hanna, \& Kurth, 1997). The presence of hydrocolloids as part of the coating formulation used has also been reported to further enhance reduction of oil uptake in fried foods (Blibech, Neifar, Kamoun, Mbarek, \& Ellouze-Ghorbel, 2013; García, Ferrero, Bértola, Martino, \& Zaritzky, 2002; Garmakhany, Mirzae, Nejad, \& Maghsudlo, 2008; Singthong \& Thongkaew, 2009). Hydrocolloids are long chain polymers (polysaccharides and proteins) that form viscous dispersions and/or gels when dispersed in water. The basis of their functional effect in food applications is that they have a high affinity for water. Example of hydrocolloids often reported as the main ingredient or part of coating formulation include xanthan, methylcellulose derivatives, guar gum, gum tragacanth, locust bean gum, etc. These hydrocolloids are used in small quantities while preparing edible film or batter coatings. However, the use of starch as a hydrocolloid in breading or as a component of breading formula is not commonly reported.

In this article, we have reported our findings on the use of SAP as a breading material in fried yam chip production. The objects of the article were to determine how drying temperature and starch content affect the specific functional properties of the SAP related to fried food applications and to establish the optimal drying conditions required to maximize the quality of SAP-coated fried yam chips.

\section{Material and methods}

\section{Materials}

The fresh eggs used in this research were purchased once from a poultry farm near the University of Agriculture, Abeokuta, Ogun State, Nigeria. Native 
Table 1. Coded and actual values of the drying variables.

\begin{tabular}{lccccc}
\hline & \multicolumn{5}{c}{ Standardized levels* } \\
\cline { 2 - 6 } Independent variables & -1.414 & -1 & 0 & +1 & +1.414 \\
\hline Drying temperature $\left({ }^{\circ} \mathrm{C}\right)$ & 35.86 & 40.00 & 50.00 & 60.00 & 64.14 \\
Starch content $(\%)$ & 5.86 & 10.00 & 20.00 & 30.00 & 34.14 \\
\hline
\end{tabular}

${ }^{*} a=1.414$ (the coded axial distance from the center point).

cassava starch used in this research was procured from Lafenwa Market in Abeokuta, Ogun State, Nigeria.

\section{Starch-albumen powder (SAP) production}

The influence of drying temperature and level of starch inclusion at five levels and constant air velocity was studied using two-factor central composite rotatable experimental design. Since denaturation of protein and starch gelatinization can occur rapidly at temperatures above $60^{\circ} \mathrm{C}$; the drying temperature of 40 to $60^{\circ} \mathrm{C}$ was used. The actual values of the coded variables and the various combinations of the process variables are shown in Table 1.

The method described by Shittu et al. (2010) was followed, with some modifications to make SAP. The eggs were washed, broken manually, and the egg white (albumen) was carefully separated from the yolk with minimum yolk contamination. The egg albumen was then mixed gently without foaming with native cassava starch for about $60 \mathrm{~s}$ in a Kenwood laboratory size blender, poured on a flat tray, and dried in a locally fabricated convective dryer preset at different temperatures and constant air velocity of $4.5 \mathrm{~m} / \mathrm{s}$. The dried flakes obtained were then milled into powder.

\section{Moisture content}

The moisture content of the samples was determined according to AOAC method 925.09 (AOAC, 2000). Five grams of the samples (SAP and fried yam chips) were weighed using a sensitive balance (METTLER PM 400, MetlerToledo, Switzerland) into petri dishes of known weight, dried at $105^{\circ} \mathrm{C}$ for 5 $\mathrm{h}$, cooled in glass desiccators, and weighed again. Analyses were replicated thrice. Moisture contents were calculated as percent of weight loss after drying on dry basis.

\section{Fat absorption capacity of SAP}

Fat absorption capacity was determined using the method described by Beuchat (1977) with little modification as reported by Shittu and Ikpasa (2006). One gram of the SAP sample was mixed with $10 \mathrm{ml}$ of vegetable oil 
in a weighed centrifuge tube. The slurry was then agitated in a vortex mixer for $2 \mathrm{~min}$, allowed to stand at $28^{\circ} \mathrm{C}$ for $30 \mathrm{~min}$, and then centrifuged at 5000 rpm for $20 \mathrm{~min}$. The clear supernatant was thereafter decanted and discarded while the adhering drops of oil were removed. The tube was then weighed and the weight of the oil absorbed by $1 \mathrm{~g}$ of the SAP sample was calculated and expressed as the fat absorption capacity. Duplicate analysis was done.

\section{Water absorption capacity of SAP}

This was determined using the method described by Beuchat (1977) with some modification as reported by Shittu and Ikpasa (2006). One gram of the SAP sample was mixed with $10 \mathrm{ml}$ distilled water in an already weighed centrifuge tube. The slurry was then agitated in a vortex mixer for $2 \mathrm{~min}$, allowed to stand at $28^{\circ} \mathrm{C}$ for $30 \mathrm{~min}$, and then centrifuged at $5000 \mathrm{rpm}$ for 20 min. The clear supernatant was thereafter decanted and discarded while the adhering drops of water were also removed. The tube was then weighed and the weight of water absorbed by $1 \mathrm{~g}$ of the SAP sample was calculated and expressed as the water absorption capacity. Analyses were done in duplicate.

\section{Coating pickup}

The coating pickup was measured after coating but before frying. This was determined using the method published by Hsia et al. (1992) as reported by Maskat et al. (2005). The weight of the yam slice before (Y) and after coating (C) were recorded. Analyses were done in triplicate. The percentage of coating pick-up was thereafter calculated as:

$$
\% \text { Coating Pickup }=\frac{100 \times(C-Y)}{Y}
$$

\section{Preparation of fried yam chips}

Yam slices (about $10 \mathrm{~mm}$ ) were prepared according to the method of Sobukola et al. (2008). Thereafter, the chips were coated with SAP by dropping the slices into the powder inside a covered plastic bowl and shaken for about $1 \mathrm{~min}$. The coated samples were then deep-fat fried with palm olein oil as the frying medium in a deep-fat fryer (model S-516, M/S Assudamal and Asons Ltd, Hong Kong, China) with temperature control of $\pm 1^{\circ} \mathrm{C}$ at a temperature of $180^{\circ} \mathrm{C}$ for $3 \mathrm{~min}$. Excess oil was allowed to drain off the fried chips for about $50 \mathrm{~s}$ (Krokida et al., 2000). 


\section{Oil uptake in coated fried yam chips}

The fat content was determined using the method described by AOAC (2000) with slight modification. The dried samples were weighed and pre-soaked in petroleum ether for $48 \mathrm{~h}$ before extraction in Soxhlet apparatus for $4 \mathrm{~h}$. After extraction, the solvent was evaporated by drying in an oven, cooled in desiccators, and weighed. Triplicate analyses were done. The oil content was then calculated as follows:

$$
\% \text { Oil content }=\frac{100 \times(X-Y)}{X}
$$

Where $\mathrm{X}$ is initial weight of sample before extraction and $\mathrm{Y}$ is the final weight of sample after extraction.

\section{Color of the coated fried yam chips}

The CIELab color parameters $\left(L^{*}, a^{*}\right.$, and $\left.b^{*}\right)$ of the fried chip were determined according the method reported by Shittu et al. (2010). The samples were snapped using a Sony digital camera with resolution of 13.6 Megapixels (model No DSC-W300) under constant daylight (fluorescent light) conditions. Digital images of each side of the four fried chips were cropped, making a total of eight per treatment. The color parameters were determined using CorelDraw Graphics Suite X5 software (Ottawa, ON, Canada). Analyses were done as four replicates. The browning index (BI) was thereafter calculated using the formula below:

$$
\begin{gathered}
\mathrm{BI}=\frac{100 \times(X-0.31)}{0.17} \\
\mathrm{X}=\frac{\left(a^{*}\right)+1.75\left(L^{*}\right)}{5.645\left(L^{*}\right)+\left(a^{*}\right)-3.012\left(b^{*}\right)}
\end{gathered}
$$

where $L^{*}$ is lightness color parameter, $a^{*}$ is redness color parameter, and $b^{*}$ is yellowness color parameter.

\section{Sensory acceptability}

Samples of the coated fried yam slices and an uncoated fried yam slices were presented randomly to a 50-member panelist group to evaluate the product based on appearance, taste, texture, flavor, and the overall acceptability of the samples using a 9-point hedonic scale with 1 for "dislike extremely" and 9 for "like extremely." The sensory evaluation was conducted under a constant lighting condition in a sensory analysis laboratory. Panelists were served the product warm. Also, drinking water was provided for palate refreshment between sample tasting. 


\section{Data analyses}

All the experimental trials were carried out in triplicates. The experimental data were fitted to a second order regression model of the form:

$$
y=\beta_{o}+\sum_{j=1}^{k} \beta_{j} X_{j}+\sum_{j=1}^{k} \beta_{j j} X_{j}^{2}+\sum_{i=1}^{k} \sum_{j=1}^{k} \beta_{i j} X_{i} X_{j}+\varepsilon
$$

$\mathrm{X}_{\mathrm{i}}$ and $\mathrm{X}_{\mathrm{j}}$ are the terms of independent factor (i.e. starch content and drying temperature, respectively) while $\beta_{0}, \beta_{\mathrm{i}}, \beta_{\mathrm{j}}$, and $\beta_{\mathrm{ij}}$ are the regression coefficients for intercept, linear, quadratic, and interaction coefficients, respectively, and are coded independent variable, $\varepsilon$ is the error term. The parameters of response surface regression equations were determined using Design Expert 7 (Stat-Ease Inc., Minneapolis, MN, USA). Correlations between the independent variables and the dependent variables were also studied using SPSS 15.0 Package (SPSS Inc., Chicago, IL, USA).

\section{Results and discussion}

\section{Functional properties of SAP}

The moisture content (MC) of the SAP powder, which ranged between 4.46 and $8.10(\%, \mathrm{db})$, were significantly different $(p<0.05)$. These values are within the range needed for shelf stability of powdered products. The water (WAC) and oil absorption (OAC) capacities also ranged from 1.04 to 1.33 and 0.86 to $1.18 \mathrm{~g} / \mathrm{g}$, respectively. These values are comparable with those reported for SAP in our previous study (Shittu et al., 2010). Only the OAC of SAP was affected by the main effect of drying temperature (Table 2), but the quadratic effect of temperature affected all three properties. The starch content of the SAP only affected the coating pick-up (CPU). The observed increase in OAC with drying temperature (DT) above $50^{\circ} \mathrm{C}$ (Figure 1) might be due to increased heat denaturation and dissociation of the protein constituents that could have unmasked the non-polar residues from the interior of the protein molecule.

Since coating powder is used on a wet surface, the water absorption characteristics may be important to maximize coating pick-up. Similarly, reduced oil absorption capacity may also be important to reduce oil uptake during frying. Considering the Pearson's correlation values, WAC showed insignificant linear correlation with coating pick-up, as it was similarly observed for OAC and oil uptake (Table 3).

\section{Color of fried yam chips}

The L-values measured on a scale of 0 (dark) to 120 (light) for fried chips ranged between 90 and 102. Also, the BI values, which are an indicator of 
Table 2. Response surface regression parameters of SAP and coated fried chips properties.

\begin{tabular}{lcccccccc}
\hline Term & $\mathrm{MC}$ & $\mathrm{WAC}$ & $\mathrm{OAC}$ & $\mathrm{CPU}$ & $\mathrm{L}^{*}$ & $\mathrm{BI}$ & $\mathrm{OU}$ & $\mathrm{MCC}$ \\
\hline Constant & 50.46 & -1.120 & 2.750 & 27.60 & 113.1 & -16.55 & 116.9 & -67.88 \\
Temperature (T) & -1.56 & $9.2 \mathrm{E}-02$ & $-7.7 \mathrm{E}-02^{*}$ & -0.42 & $-1.10 \mathrm{E}-02$ & 4.11 & $-2.53^{*}$ & $2.47^{*}$ \\
Starch (S) & -0.58 & $1.2 \mathrm{E}-02$ & $-7.0 \mathrm{E}-02$ & $-0.98^{*}$ & $1.43^{*}$ & -4.37 & $-3.31^{* *}$ & $3.89^{* *}$ \\
$\mathrm{~T} \times \mathrm{T}$ & $1.5 \mathrm{E}-02^{* *}$ & $-9.7 \mathrm{E}-04^{* *}$ & $8.2 \mathrm{E}-04^{*}$ & $2.2 \mathrm{E}-02$ & $1.4 \mathrm{E}-02^{*}$ & $-4.7 \mathrm{E}-02$ & $1.9 \mathrm{E}-02$ & $-1.6 \mathrm{E}-02$ \\
$\mathrm{~S} \times \mathrm{S}$ & $1.3 \mathrm{E}-02^{* *}$ & $-4.9 \mathrm{E}-04$ & $1.7 \mathrm{E}-04$ & $8.7 \mathrm{E}-02$ & $-3.6 \mathrm{E}-02$ & $2.0 \mathrm{E}-02$ & $2.0 \mathrm{E}-02^{*}$ & $-4.8 \mathrm{E}-02^{* *}$ \\
$\mathrm{~T} \times \mathrm{S}$ & $9.8 \mathrm{E}-04$ & $2.2 \mathrm{E}-04$ & $6.1 \mathrm{E}-06$ & $1.2 \mathrm{E}-02$ & $-2.6 \mathrm{E}-02^{*}$ & $4.3 \mathrm{E}-02$ & $4.4 \mathrm{E}-02^{* *}$ & $-3.4 \mathrm{E}-02^{*}$ \\
$\begin{array}{l}\text { Goodness of fit parameters } \\
\text { Sig. P }\end{array}$ & 0.002 & 0.042 & 0.160 & 0.656 & 0.003 & 0.147 & 0.020 & 0.002 \\
$\mathrm{R}^{2}(\%)$ & 89.63 & 74.40 & 61.63 & 32.50 & 88.63 & 62.72 & 80.46 & 90.03 \\
$\begin{array}{l}\text { PRESS } \\
\text { Critical values of independent variables }\end{array}$ & 21.23 & 0.197 & 0.315 & 12.29 & 249.8 & 54.15 & 249.8 & 250.1 \\
$\begin{array}{l}\text { Drying Temperature } \\
\quad \text { (Min) }\end{array}$ & 51.3 & 64.1 & 46.7 & $\mathrm{ND}$ & 64.1 & 35.9 & 35.9 & 35.9 \\
$\begin{array}{l}\text { Starch Content } \\
\quad \text { (Min) }\end{array}$ & 20.4 & 5.9 & 20.4 & $\mathrm{ND}$ & 34.1 & 34.1 & 34.1 & 5.8 \\
$\begin{array}{l}\text { Drying Temperature } \\
\quad \text { (Max) }\end{array}$ & $\mathrm{ND}$ & 50.0 & 64.1 & 64.1 & 35.9 & 46.1 & $\mathrm{ND}$ & $\mathrm{ND}$ \\
$\begin{array}{l}\text { Starch Content } \\
\quad(M a x)\end{array}$ & $\mathrm{ND}$ & 23.3 & 5.9 & 34.1 & 34.1 & 5.9 & $\mathrm{ND}$ & $\mathrm{ND}$ \\
\hline
\end{tabular}

ND: Not determined.

WAC: Water absorption capacity of SAP (\%), MC: Moisture content of SAP (\%), L* chip's lightness, OU: Oil uptake of chips (\%), MCC: Moisture content of fried chips (\%), BI: Brownness index, Acc: Sensory acceptability.

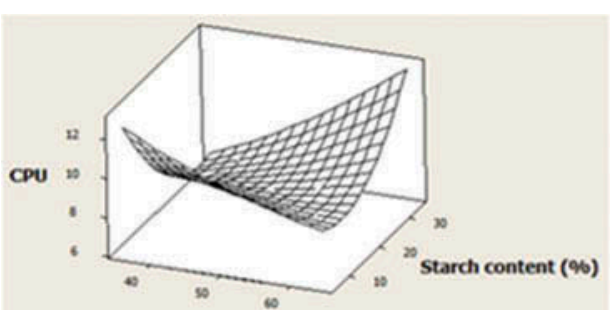

Drying temperature (deg $c)$

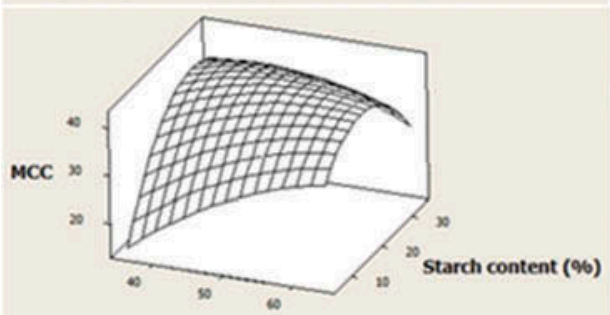

Drying temperature (deg C)

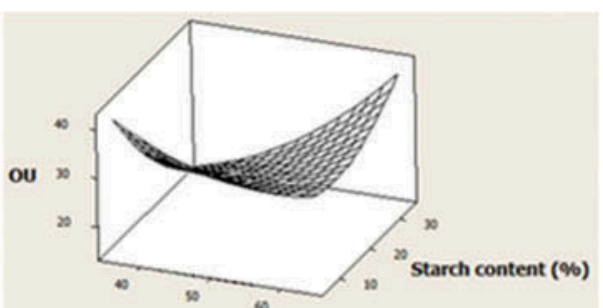

Drying temperature (deg C)

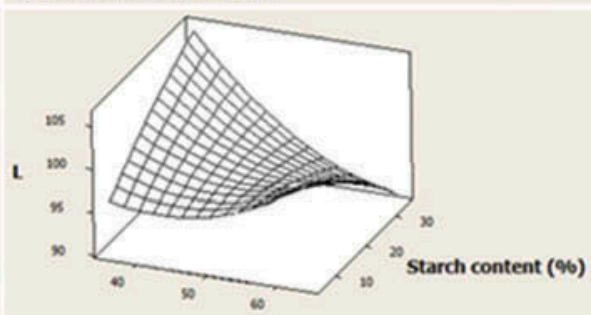

Drying temperature (deg C)

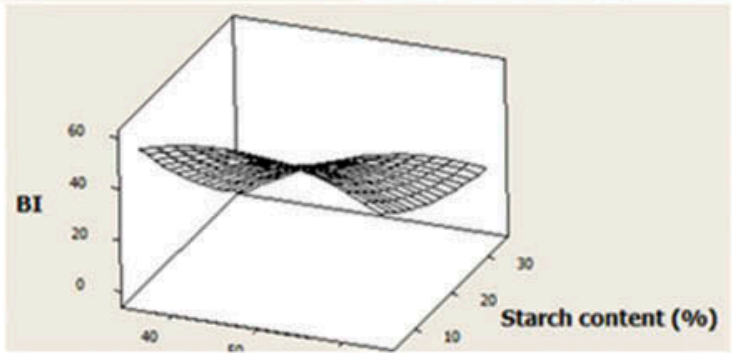

Figure 1. Response surface curves of the SAP and fried chips properties (CPU: Coating pick-up (\%), OU: Oil uptake (\%), MCC: Moisture content of fried chip, L: Crust lightness). 
Table 3. Pearson's correlation of SAP and coated fried chips properties.

\begin{tabular}{lccrcrrrrr}
\hline Parameter & MC & WAC & OAC & CPU & $L^{*}$ & BI & OU & MCC & ACC \\
\hline MC & 1.00 & & & & & & & & \\
WAC & $-0.86^{* *}$ & 1.00 & & & & & & & \\
OAC & 0.40 & $-0.63^{*}$ & 1.00 & & & & & & \\
CPU & 0.49 & -0.51 & 0.37 & 1.00 & & & & & \\
L* & 0.18 & -0.18 & 0.12 & $-0.57^{*}$ & 1.00 & & & & \\
BI & -0.01 & -0.15 & -0.03 & 0.31 & -0.18 & 1.00 & & & \\
OU & 0.38 & -0.53 & 0.52 & $0.73^{*}$ & -0.48 & 0.35 & 1.00 & & \\
MCC & $-0.72^{* *}$ & 0.55 & -0.01 & $0.66^{* *}$ & 0.16 & -0.29 & $-0.59^{*}$ & 1.00 & \\
ACC & -0.10 & -0.19 & 0.31 & -0.17 & 0.16 & 0.02 & 0.05 & 0.20 & 1.00 \\
\hline
\end{tabular}

WAC: Water absorption capacity of SAP (\%), MC: Moisture content of SAP (\%), L* chip's lightness, OU: Oil uptake of chips (\%), MCC: Moisture content of fried chips (\%), BI: Brownness index, Acc: Sensory acceptability.

degree of color purity as well as measure of browning of the chips, ranged between 12 and 97. These values differed significantly $(p<0.05)$ among the chip samples. Significant effect of starch content (SC) and its interaction with the drying temperature (DT) were observed on L-value (Table 3). Increased starch content produced lighter chips (Figure 2). BI was neither influenced by drying temperature nor starch content. This might be due to the fact that BI value is also dependent on other color parameters $\mathrm{a}^{*}$ and $\mathrm{b}^{*}$, as shown in Equations 3 and 4. Based on the values of $a^{\star}(-3$ to 3$)$ and $b^{*}$ (11 to 40$)$, the chips are more yellowish than reddish, which underscores why the BI values were generally low. Moreover, non-enzymatic browning (or Maillard's) reaction takes place only in the presence of amino acids and reducing sugar at a high

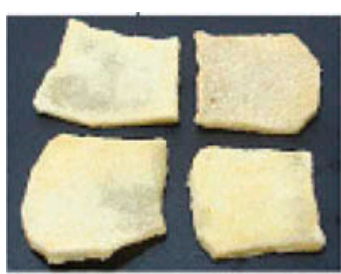

$35.8^{\circ} \mathrm{C}$

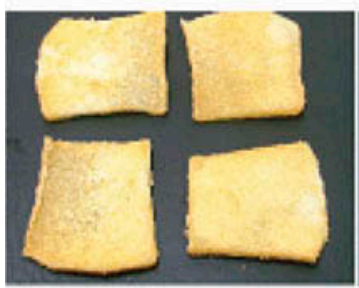

5.85\% Starch

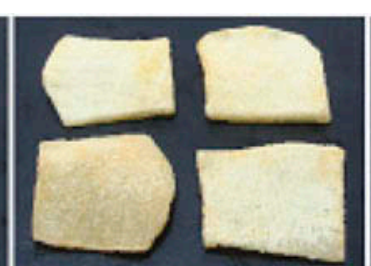

$50^{\circ} \mathrm{C}$

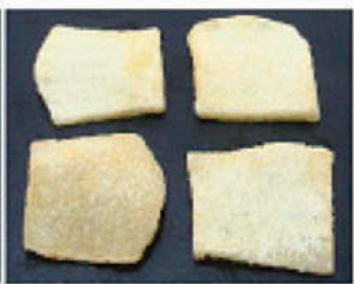

$20 \%$ Starch

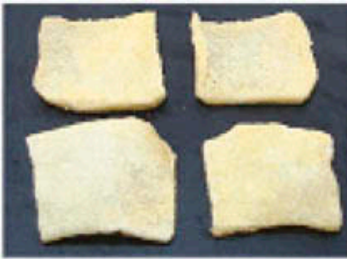

$64.1^{\circ} \mathrm{C}$

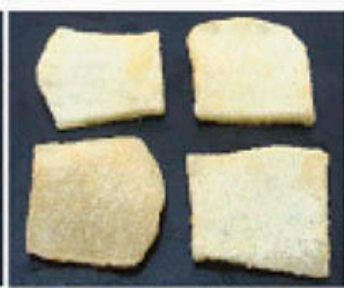

$34.14 \%$ Starch

Figure 2. Effect of drying temperature and starch content on the appearance of SAP coated fried chips. 
temperature. In addition, pure starches, as used in this study, contain no reducing sugar. The little browning that was observed may be due to the sugar in the liquid albumen. This may be responsible for the observed reduction of BI value with SC (Figure 2).

\section{Moisture retention and oil uptake of fried yam chips}

As shown in Table 3, the MC of SAP had a significant negative correlation with WAC. This means that a greater level of drying of SAP could lead to higher moisture absorption during use and vice versa. This result has implications for fried food's textural and taste properties. For example, increased moisture content would reduce the crispiness of fried chips. The oil uptake (OU) was predominantly due to the diffusion of frying oil into chips through the coating layer. The OU value ranged between 19 and $34 \%$. The OU was significantly affected by the DT and SC. Increased DT caused reduced oil uptake, whereas it was increased with SC (Figure 1). Increased drying temperature gave higher moisture content in fried chips (MCC), but this increment is starch content dependent. This is evident with the saddled response shown by OU to starch and drying temperature in Figure 1. The production of SAP at a lower temperature favored lower OU, probably due to higher moisture in SAP, which could have served as a physiochemical barrier against oil ingression into yam tissue. As reflected by the quadratic regression coefficient of starch (Table 2), the main effects of DT and SC of SAP were negative on CPU and OU, whereas their interactive effect was positive. This explains why a saddled response was observed similarly for the CPU and OU (Figure 1). Practically, the saddled response surface indicates antagonistic effects at some levels of the independent variable. Also, it further corroborates the positive correlation observed between CPU and OU $(r=0.73$, $p<0.05)$. Thus, if the goal of using SAP coating is mainly to reduce oil uptake, then less starch (or more egg white) should be incorporated. The increased amount of proteins in dry coating could have served to block fat absorption during deep-fat frying (Pszczola, 2005).

\section{Sensory properties of fried yam chips}

Coating yam chips with SAP significantly improved the sensory acceptability scores for taste (6.68-7.10) and flavor (6.58-7.28) of the products when compared with those without coating (control) having respective scores of 5.10 and 5.72 for taste and flavor. The trend of sensory scores with varying values of the independent variables is better pictured from response surface plots (Figure 3). The stronger effect of SC when compared with that of DT is evident from the surface plots that show greater responsiveness of the scores to 

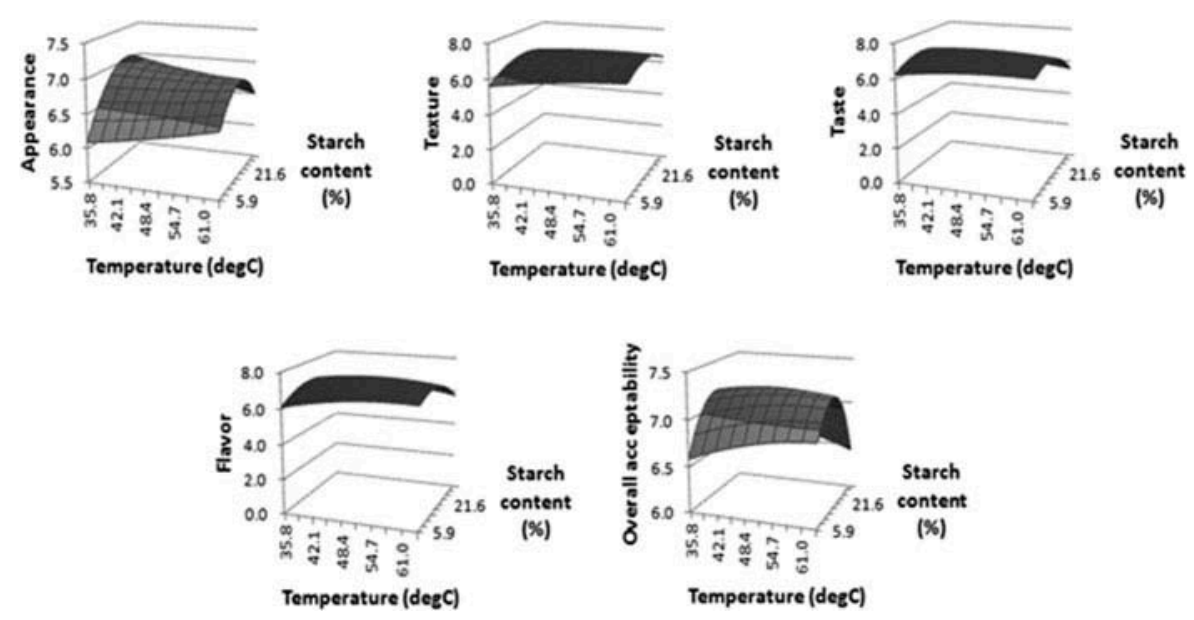

Figure 3. Response surface plot of sensory scores for coated fried yam chips.

Table 4. Response surface regression parameters of chip's sensory properties.

\begin{tabular}{lccccc}
\hline Term & Appearance & Texture & Taste & Flavor & Overall acceptability \\
\hline Constant & 5.067 & 2.218 & 2.750 & 0.894 & 4.688 \\
Temperature (T) & $8.28 \mathrm{E}-02$ & 0.097 & 0.108 & 0.173 & 0.050 \\
Starch (S) & 0.150 & 0.177 & 0.190 & 0.206 & 0.136 \\
$\mathrm{~T} \times \mathrm{T}$ & $1.05 \mathrm{E}-04$ & $-6.40 \mathrm{E}-03$ & $-8.74 \mathrm{E}-04$ & $-1.40 \mathrm{E}-03$ & $-3.46 \mathrm{E}-04$ \\
$\mathrm{~S} \times \mathrm{S}$ & $-2.09 \mathrm{E}-03$ & $-9.00 \mathrm{E}-04$ & $-1.00 \mathrm{E}-03$ & $-1.40 \mathrm{E}-03$ & $-7.00 \mathrm{E}-04$ \\
$\mathrm{~T} \times \mathrm{S}$ & $-1.00 \mathrm{E}-03$ & $-3.09 \mathrm{E}-03$ & $-4.12 \mathrm{E}-03$ & $-3.85 \mathrm{E}-03$ & $-2.69 \mathrm{E}-03$ \\
Sig. P & 0.423 & 0.295 & 0.551 & 0.606 & 0.320 \\
$\mathrm{R}^{2}(\%)$ & 69.6 & 77.3 & 47.9 & 50.2 & 34.8 \\
PRESS & 1318.8 & 684.57 & 4504.58 & 6298.19 & 1893.12 \\
\hline
\end{tabular}

the former than the latter. The response of sensory score to SC is entirely quadratic. There is always a maximum amount of SC, above which there was a decline in the sensory scores. Texture was the least affected sensory attribute by SC, while it was stronger on the appearance and overall acceptance of the fried chips. Considering the importance of each sensory attribute on the overall acceptance of the coated chips, it follows the order of taste $>$ flavor $>$ texture $>$ appearance, as determined by their Pearson's correlation coefficients.

The response surface regression gives a quantitative assessment of how each independent factor and their interactions affect any response variable. The regression coefficient of each factor measures the weight and the direction to which it pulls the response variable. The regression equations for predicting acceptability of the chips had coefficients of determination $\left(\mathrm{R}^{2}\right)$ ranging from 29.5 to $77.3 \%$ (Table 4). This result indicates that the response of taste, flavor, and overall acceptance to the DT and SC cannot be adequately modeled by a quadratic equation when compared with that of appearance and texture. However, as shown in Figure 2, the main effect of DT was positive on the appearance and overall preference at a lower SC. 
Table 5. Global optimum conditions.

\begin{tabular}{lcc}
\hline Parameter & Goal & SAP coated chip \\
\hline Temperature $\left({ }^{\circ} \mathrm{C}\right)$ & - & 40.00 \\
Starch $(\%)$ & - & 11.28 \\
Moisture content of fried chip (\%) & Minimize & 28.23 \\
Oil uptake of fried chip (\%) & Minimize & 19.41 \\
Overall acceptability of fried chip & Maximize & 7.00 \\
Desirability of the optimal conditions & - & 0.8 \\
\hline
\end{tabular}

\section{Optimization of fried chips quality}

Processing variables should be easily manipulated to achieve a tailor-made product for specific end uses. This is the reason why modeling and optimization of a process based on certain product constraints is of practical interest. In this article, optimizing the quality of fried chips based on the two independent process variables used in producing SAP was the main goal. The critical values of the process variables to minimize or maximize the SAP properties are presented in Table 2. As the results reflect, the DT and SC required for minimizing and maximizing different SAP properties are different. The practical implication of this result is that it should be possible to produce SAP with different functional properties appropriate for different food applications. However, to optimize the quality of SAP for use as fried yam chip coatings, the set objective was to maximize the overall sensory acceptability and minimize oil uptake and moisture content of the fried chips. Minimization of oil content is necessary to reduce the health risk of excessive fat consumption, while minimizing the moisture content would help to enhance crispiness and stability against microbial spoilage if the chips are packaged and kept for long after frying. The optimal values of these respective parameters are shown in Table 5 . This gave predicted optimal DT and $\mathrm{SC}$ of $40^{\circ} \mathrm{C}$ and $11.3 \%$, respectively.

\section{Conclusions}

This study has shown that the two independent processing variables, namely drying temperature and starch content, could be manipulated to achieve SAP with functional properties useful for many food applications. The use of SAP as a coating material improved the taste and flavor appeal of fried yam chips when compared to uncoated fried chip samples. Optimal performance of SAP as a coating material in fried yam chip production can be achieved by using drying temperature and starch content of $40^{\circ} \mathrm{C}$ and $11.3 \%$, respectively. Other potential applications of SAP as a coating/breading material in some food applications are currently being considered in our laboratory. 


\section{Nomenclature}

$\begin{array}{lll}\text { MC } & \text { Moisture content of SAP } & \%, \mathrm{db} \\ \text { WAC } & \text { Water absorption capacity of SAP } & \text { g/g solid } \\ \text { OAC } & \text { Oil absorption capacity of SAP } & \text { g/g solid } \\ \text { CPU } & \text { Coating pick up of un-fried chip } & \%, w / w \\ \text { L } & \text { Lightness of fried chip } & \\ \text { BI } & \text { Brownness index of fried chip } & \\ \text { OU } & \text { Oil uptake of fried chip } & \%, w / w \\ \text { MCC } & \text { Moisture content of fried chip } & \%, w / w\end{array}$

\section{Funding}

This study was supported by a grant of the Research and Development Council of the Federal University of Agriculture, Abeokuta (RG 219).

\section{References}

Abu-Ali, J. M. (2004). Food coating applications. In Electrostatic atomization, nonelectrostatic coating and electrostatic powder coating (Doctoral dissertation). Ohio State University, Columbus, $\mathrm{OH}$.

Albert, S., \& Mittal, G. S. (2002). Comparative evaluation of edible coatings to reduce fat uptake in a deep-fried cereal product. Food Research International, 35, 445-458. doi:10.1016/S0963-9969(01)00139-9

Alimi, B. A., Shittu, T. A., \& Sanni, L. O. (2014). Effect of hydrocolloids and egg content on sensory quality of coated fried yam chips. Journal of Culinary Science \& Technology, 12(2), 168-180. doi:10.1080/15428052.2014.880097

Alimi, B. A., Shittu, T. A., Sanni, L. O., \& Arowolo, T. A. (2013). Effect of some hydrocolloids as adjuncts on the quality of whole egg or egg white coated fried yam chips. Journal of Food Agricultural Environment, 11, 19-24.

AOAC. (2000). Official methods of analysis (17th ed.). Gaithersburg, MD: AOAC International.

Bergquist, D. H. (1986). Egg dehydration. In E. J. Stadelman \& O. J. Cotterill (Eds.), Egg science and technology (pp. 285-319). New York, NY: Haworth Press.

Beuchat, L. R. (1977). Functional and electrophoretic characteristics of succinylated peanut flour proteins. Journal of Agricultural Food Chemistry, 25, 258-261. doi:10.1021/ jf60210a044

Blibech, M., Neifar, M., Kamoun, A., Mbarek, B. B., \& Ellouze-Ghorbel, R. (2013). Enhancing potato chips quality by optimizing coating and frying conditions using response surface methodology. Journal of Food Processing and Preservation, (Article first published online). doi:10.1111/jfpp.12101

García, M. A., Ferrero, C., Bértola, N., Martino, M., \& Zaritzky, N. (2002). Edible coatings from cellulose derivatives to reduce oil uptake in fried products. Innovative Food Science \& Emerging Technologies, 3, 391-397. doi:10.1016/S1466-8564(02)00050-4 
Garmakhany, A. D., Mirzae, H. O., Nejad, M. K., \& Maghsudlo, Y. (2008). Study of oil uptake and some quality attributes of potato chips affected by hydrocolloids. European Journal of Lipid Science and Technology, 110, 1045-1049. doi:10.1002/ejlt.v110:11

Gennadios, A., Hanna, M. A., \& Kurth, L. B. (1997). Application of edible coatings on meats, poultry and seafoods: A review. LWT-Food Science and Technology, 30, 337-350. doi:10.1006/fstl.1996.0202

Hsia, H. Y., Smith, D. M. \& Steffe, J. F. (1992). Rheological properties and adhesion characteristics of flour-based batters for chicken nuggets as affected by three hydrocolloids. Journal of Food Science, 571, 16-24.

Krokida, M. K., Oreopoulou, V., \& Maroulis, Z. B. (2000). Water loss and oil uptake as a function of frying time. Journal of Food Engineering, 44, 39-46.

Maskat M. Y., Yip H. H. \& Mahali H. M. (2005). The performance of a methyl cellulosetreated coating during the frying of a poultry product. International Journal of Food Science and Technology, 40, 811-816.

Mohr, K. H., Kleinschmidt, T. H., \& Borgwardt, J. (1987). Concentration of egg white by ultrafiltration. Food/Nahrung, 31(4), 345-347. doi:10.1002/(ISSN)1521-3803

Pszczola, D. E. (2005). New batters and breading go beyond just crumbs. Food Technology, 59(10), 49-60.

Satin, M. (2014). Functional properties of starches. FAO Agricultural and Food Engineering Technologies Service. Retrieved from http://www.fao.org/ag/magazine/pdf/starches.pdf

Shittu, T. A., Idowu, M. A., \& Ademosun, O. O. (2010). Production of dried starch-albumen powder: Effect of temperature and starch on some functional properties. Journal of Food Processing and Preservation, 34, 385-400. doi:10.1111/(ISSN)1745-4549

Shittu, T. A., \& Ikpasa, S. E. (2006). Effect of starch pretreatment on the functional properties of oven dried starch-albumen powder. Nigerian Drying Symposium Series, 2, 85-91.

Silversides, F. G., \& Scott, T. A. (2001). Effect of storage and layer age on quality of eggs from two lines of hens. Journal of Poultry Science, 80, 1240-1245. doi:10.1093/ps/80.8.1240

Singthong, J., \& Thongkaew, C. (2009). Using hydrocolloids to decrease oil absorption in banana chips. LWT-Food Science and Technology, 42, 1199-1203. doi:10.1016/j. lwt.2009.02.014

Sobukola, O. P., Awonorin, S. O., Sanni, L. O., \& Bamiro, F. O. (2008). Optimization of blanching conditions prior to deep fat frying of yam slices. International Journal of Food Properties, 11, 379-391. 